\title{
Combining Equity Country Selection Strategies
}

\author{
Adam Zaremba ${ }^{1}$
}

ABSTRACT

The recent increase in passive investment products has provided investors with easy access to international markets. The basic motivation of this paper is to offer new tools to investors who want to allocate assets across countries. This study investigates the performance of equity country selection strategies based on a combination of theoretically and empirically motivated variables. Thus, we create portfolios and assess their performance using asset pricing models. The empirical examination is based on data from 78 countries from 1999 to 2015. The strategies that are based on the earnings-toprice (EP) ratio, the turnover ratio, and skewness prove to be useful tools for international investors. Furthermore, portfolios from sorts on the blended rankings of skewness combined with the EP ratio or the turnover ratio are also characterized by an attractive risk-return ratio. However, joint strategies do not outperform strategies that are based on single metrics. Consequently, we argue that investors would be better off building a diversified portfolio rather than combining their options into one strategy because of the low correlation among returns on single-variable strategies.

KEY WORDS: $\quad$ country selection strategies, asset pricing, cross section of stock returns, value investing, momentum, skewness preference, liquidity premium, turnover ratio, international investments.

JEL Classification: G11, G12, G15

1 Poznan University of Economics and Business, Poland

\section{Introduction}

The financial literature offers a growing number of equity country selection strategies for international investors. Most of these strategies are parallels of formerly discovered stock-level cross-sectional effects and anomalies. Balvers and Wu (2006), Bhojraj and Swaminathan (2006), and Asness, Moskowitz and Pedersen (2013) have found evidence for country-level momentum and reversal effects. Macedo (1995), Kim (2012), and Zaremba (2015a) have argued that stock markets with low

Correspondence concerning this article should be addressed to: Adam Zaremba, Poznan University of Economics and Business, al. Niepodleglosci 10, 61-875 Poznan, Poland E-mail: adam.zaremba@ue.poznan.pl fundamentals relative to price outperform those with high fundamentals relative to price. Keppler and Traub (1993) and Keppler and Encinosa (2011) have concluded that, regarding country equity selection, "small is beautiful”. Zaremba (2015b; 2015c) has examined a number of inter-market anomalies related to various quality and risk metrics. Finally, Harvey (2000) and Zaremba and Nowak (2015) have suggested that the "skewness preference" phenomenon may be important for asset pricing not only at the stock level but also at the country level. The number of country-level anomalies discovered constantly increases, but it remains relatively modest in comparison with the abundant literature on stock-level effects. Only a few recent papers review dozens (Jacobs, 2015) or hundreds (Harvey, Liu, \& Zhu, 2015) of stock- 
level anomalies. It appears that the analogous development of country-level studies are in the future.

Many of the above-described stock market anomalies are commonly used by the fund management industry. These types of strategies are usually built into the quantitative trading strategies used by hedge funds, mutual funds, or smart-beta products (Pedersen, 2015). Nonetheless, it is not an easy task to find one's path through this zoo of stock market anomalies and to properly utilize them in portfolio management (Hsu \& Kalesnik, 2014). In practice, stock-level portfolio managers take one of the two following approaches: they design a portfolio of independent strategies and achieve risk reduction through low correlation among them, or they blend strategies into one portfolio to benefit from the fact that certain strategies strengthen each other. The second approach is usually based on an average of the rankings or $z$-scores of a number of variables related to various cross-sectional strategies, and this is commonly examined in stock-level studies. A few papers can serve as examples of this. Novy-Marx (2013) has combined sorts on gross profitability with the bookto-market ratio, Piotroski (2000) has mixed a few financial ratios to form the well-known F-score, and Asness Frazzini and Pedersen (2014) has blended a large number of quality metrics to implement a quality-minus-junk strategy. Although the combinations of cross-sectional effects are commonly investigated in stock-level studies, they have not been examined from a country-level perspective. In other words, we still do not know whether it is beneficial for investors to blend country-selection strategies with each other or if it is better to build a portfolio of stand-alone strategies. The main objective of this paper is to fill this gap in the literature.

This study has two basic objectives. The first objective is to re-examine a number of cross-sectional equity country selection strategies that have been, thus far, best motivated, both theoretically and empirically, in the previous literature. The second objective is to investigate whether the combinations of these strategies provide returns that are superior to stand-alone strategies. In other words, we test whether it is rational to blend certain strategies in a portfolio or to leave them on a stand-alone basis. Thus, we build portfolios from sorts on single variables and on pairs of variables, and then we examine their performance using asset pricing models. Our tests are conducted with a sample of 78 countries using data from 1999-2015.

Our research is motivated by the profound changes that have occurred in the financial markets in recent years that have left investors without access to sufficient investment tools and strategies. Growing integration and openness to the global financial markets has increased the correlation between stock market returns across different countries (Bekaert \& Harvey, 2000; Quinn \& Voth, 2008), markedly reducing the diversification benefits for international investments (Goetzmann, Li, \& Rouwenhorst, 2005). This change has accorded greater prominence to country selection strategies as a part of the investment process, and it has coincided with the wide proliferation of passive investment products that allow for easy access to international markets (e.g., futures, index funds, and exchange-traded funds [ETFs]) (Hester, 2013). Given both the wealth of opportunities and the considerable size of the global ETF market, the range of investment tools available to ETF investors continues to appear limited. The cross-sectional strategies largely await further development; we hope that this study will be a small step that helps to reduce this discrepancy.

The key findings of this study can be summarized as follows. Among the re-examined strategies from sorts on single variables, we found that three of these, those that are based on the EP ratio, the turnover ratio, and skewness, are useful tools for international investors. Moreover, strategies based on the combined ranking of the earnings-to-price (EP) ratio with skewness and the turnover ratio with skewness were also characterized by attractive alpha and Sharpe ratios. However, the blended strategies did not outperform portfolios based on single metrics. Consequently, we argue that, given the low correlation among the returns on single-variable strategies, investors would be better off building a diversified portfolio of strategies rather than blending them into one strategy. These observations are likely important for fund pickers and money managers who have a global investment mandate.

This paper is primarily related to the literature on country-level asset allocation strategies (e.g., Asness et al., 2013; Balvers \& Wu, 2006; Bhojraj \& Swaminathan, 2006; Harvey, 2000; 2004; Keppler \& Encinosa, 2011; Keppler \& Traub, 1993; Kim, 2012; Macedo, 1995; Za- 
remba, 2015a). Nonetheless, the cross-sectional patterns in the returns are usually due to inefficiencies that cannot be easily explained away due to cross-country capital flow constraints. Thus, this research is also related to studies on international asset pricing and the integration of capital markets (e.g., Adler \& Dumas, 1983; Chaieb \& Errunza, 2007; Errunza \& Losq, 1985; Solnik \& Zuo, 2012; Solnik, 1974; Stulz, 1981a, b) as well as the home bias effect, which explains the lack of full integration in international markets (cf., Cooper, Sercu and Vanpée (2013) for a comprehensive review).

The remainder of this paper is organized into three main sections. The next section presents research methods and data sources. It is followed by a section that presents our findings. The final section concludes the paper.

\section{Data and Methods}

This study tested the performance of country portfolios formed from combinations of various metrics. Thus, in practice, we tested three separate hypotheses. First, we re-examined whether the portfolios from sorts of four separate variables (the EP ratio, momentum, skewness, and the turnover ratio) revealed a cross-sectional pattern and delivered abnormal returns. Second, we investigated whether strategies based on combinations of these metrics were also useful for international investors. Finally, we examined whether blended strategies augmented the efficient frontier of the component strategies.

This section will present the data sources and procedures used in constructing the portfolios from sorts on single and double metrics, followed by the asset pricing tests and the model we used in this study. Finally, we outline the robustness checks that were undertaken.

\section{Data Sources and Initial Preparation}

This research was based on returns in international stock market indices from 78 countries: Argentina, Australia, Austria, Bahrain, Bangladesh, Belgium, Brazil, Bulgaria, Canada, Chile, China, Colombia, Croatia, Cyprus, Czech Republic, Denmark, Egypt, Estonia, Finland, France, Germany, Greece, Hong Kong, Hungary, Iceland, India, Indonesia, Ireland, Israel, Italy, Japan, Jordan, Kazakhstan, Kenya, Kuwait, Latvia, Lebanon, Lithuania, Luxemburg, Malaysia, Malta, Mexico, Morocco, Mauritius, the Netherlands, New Zealand,
Nigeria, Norway, Oman, Pakistan, Peru, Philippines, Poland, Portugal, Qatar, Romania, Russia, Serbia, Saudi Arabia, Singapore, Slovenia, South Africa, South Korea, Spain, Sri Lanka, Sweden, Switzerland, Taiwan, Thailand, Trinidad and Tobago, Tunisia, Turkey, Ukraine, United Arab Emirates, the United Kingdom, the U.S.A., Venezuela, and Vietnam. All source data were obtained from the Bloomberg database. We used a monthly time series because it provided a sufficient number of observations to ensure the effectiveness of the tests, and it allowed us to avoid excessive exposure to micro-structure issues (de Moor \& Sercu, 2013). We adopted the MSCI indices for all the countries to maintain a consistent return computation methodology because the MSCI indices represent capitalization-weighted benchmarks that are commonly tracked worldwide. Additionally, these indices constitute the basis for numerous futures contracts and ETFs all over the world (see, e.g., MSCI, 2013). Therefore, our decision to adopt the MSCI indices helps to align this research with investment practice. These indices are constructed and managed with the goal of being fully investable from the perspective of the international institutional investor (MSCI, 2014a), and they cover approximately $85 \%$ of stock market capitalizations in the countries they represent (MSCI, 2014b). If an MSCI index was not available for a country, the second choice for an index was the Dow Jones; the third choice was the STOXX.

The returns were computed based on capitalizationweighted net total return indices. In other words, the returns were adjusted for corporate actions (i.e., splits, reverse splits, issuance rights, and others) and cash distributions to investors (i.e., dividends). The net convention of the indices means that the dividends were calculated on an after-tax basis. We used this approach to control for different tax rates on dividends in different countries. The sample period ran from January 1999 to March 2015, as available (there were 195 monthly observations). The total sample included equity markets from 78 countries; in addition, both existing and discontinued indices (e.g., MSCI Venezuela) were used to avoid a survivorship bias. A stock market was included in the sample in month $t$ when it was possible to compute returns on a given strategy with all the necessary data (i.e., its return in month $t$, its capitalization at the end of month $t$ - 1 , and the met- 
ric necessary to sort the countries for the portfolios' formation at the end of month $t$-1).

The initial index values and capitalizations were collected in local currencies; however, we acted in accordance with Liew and Vassalou (2000) and Bali, Cakici and Fabozzi (2013) who argued that comparisons using different currency units could be misleading. This argument is particularly true in emerging and frontier markets where inflation and risk-free rates are occasionally very high and differ significantly across markets. Therefore, we adopted the approach of Liu, Liu and Ma (2011), Bekaert, Harvey and Lundblad (2007), and Brown, Du, Rhee and Zhang (2008) and denominated all data in U.S. dollars (USD) such that we could obtain polled international results. To be consistent with the USD approach, the excess returns were computed over returns on a Bloomberg generic U.S. 1-month T-bill.

\section{Examined Portfolios}

We researched the performance of portfolios formed on single and double rankings of four different variables. The choice of sorting metrics was motivated by the outcomes of previous research, and we selected four recent studies on country-selection strategies that were the most reliable and the best documented.

First, a number of authors including Macedo (1995), Kim (2012), Asness et al. (2013), and Zaremba (2015a) have argued that value strategies, which were used to sort indicators such as the book-to-market ratio, the EP ratio, or the dividend yield, help to forecast future returns. Zaremba and Konieczka (2016) have found that, among various value metrics, the EP ratio is the most robust to changes in portfolio weighting schemes or return computation conventions. Thus, the first variable we employed was the EP ratio. To calculate the country-level EP ratio, we divided the weightedaverage market value of all the companies in a given index by the weighted average cumulative earnings in the prior four quarters. We weighted the companies' metrics according to the index methodology. Finally, to avoid the look-ahead bias and to assess returns in month $t$, we formed portfolios based on a lagged EP ratio from the end of month $t-4$.

Second, one of the most broadly discussed country-level strategies is momentum (Asness et al. 2013; Balvers \& Wu, 2006; Bhojraj \& Swaminathan, 2006;
Zaremba 2015a). The Achilles' heel of this strategy is the fact that it appeared to work very well for equally-weighted country portfolios and for capitalization. However, regarding liquidity-weighting, its performance appeared to be much worse (Zaremba \& Konieczka, 2016). Nevertheless, due to its popularity and extensive interest from both academics and practitioners, we decided to include momentum in this study. Zaremba and Konieczka (2016) have found that the cross-country momentum strategy works best for the 12-month sorting period; therefore, we utilized this approach. Furthermore, we skipped the standard last month to disentangle the impact of short-term reversal (Jegadeesh, 1990; Lehmann, 1990). In summary, for portfolios formed at the end of the month $t$ - 1 , the lagged momentum return was the gross index cumulative return over the period $t-12$ to $t-2$.

Third, Zaremba (2015a) as well as Zaremba and Konieczka (2016) have investigated a few country-selection strategies based on quality, inspired by Asness et al. (2014). Some of these strategies yielded promising results, but the most robust results appeared to be those based on the turnover ratio. Thus, we have also used the turnover ratio as a component strategy in this study. Thus, at the end of each month, we divided the aggregated turnover throughout the month by its total market capitalization of the given index. Next, we averaged the values over months $t-12$ to $t-1$ to obtain the turnover ratios that we used to rank the countries. The higher the turnover ratio, the higher is the market liquidity. Based on the evidence found in Zaremba and Konieczka (2016), we expected that more liquid markets would be characterized by lower returns.

The fourth component strategy was based on the skewness of past returns. Zaremba and Nowak (2015) have hypothesized that, due to the implications of the prospect theory by Tversky and Kahneman (1992), investors overvalue right-skewed return distributions and undervalue left-skewed return distributions. Thus, the country equity markets with a high positive skewness with respect to their prior returns should perform more poorly than markets with a large negative skewness. Zaremba and Nowak (2015) have found convincing evidence that confirms this supposition, showing that country-selection strategies based on skewness could be more profitable than traditional strategies that are based on value, size, and 
momentum effects. To explain this, we re-examined this strategy, in close accordance with the approach of Zaremba and Nowak (2015). In other words, we sorted countries based on the skewness of their distributions of monthly excess gross returns over the months $t-24$ to $t$ - 1 . We expected that countries with higher skewness would have lower returns.

To form portfolios from single sorts, all stock market indices were ranked against one of their underlying metrics at the end of each month $t$ - 1 : the EP ratio, momentum, the turnover ratio, or skewness. To preserve a consistent method across all four strategies, we always sorted the countries from the lowest to the highest metric. Next, we defined the $20^{\text {th }}, 40^{\text {th }}, 60^{\text {th }}$, and $80^{\text {th }}$ percentiles as breakpoints; from this, we formed five sub-groups. Finally, the indices in the respective subgroups were weighted according to their market capitalization to form portfolios. It is common in countrylevel studies to equal-weight the indices in portfolios. However, this approach has two important disadvantages. First, it overstates the importance of small and illiquid markets where it may be difficult to invest. Second, the returns on equally-weighted portfolios may be distorted by so-called returns on rebalancing or returns on diversification (Willenbrock, 2011). To overcome these difficulties, we weighted the indices according to their market capitalization. In other words, we weighted the returns in month $t$ according to the total stock market capitalization at the end of month $t$ - 1 . We subsequently added differential portfolios, in other words, zero-portfolios, that were long/ short portfolios: $100 \%$ long in the quintile of markets with the highest metric, and $100 \%$ short in the quintile of markets with the lowest metric.

The portfolios from simultaneous sorts on two variables were designed in a similar fashion as the portfolios from single sorts. However, in this case, we did not sort the markets based on their skewness or the turnover ratios. Instead, we sorted the markets based on their reverse skewness or reverse turnover ratios, that is, we multiplied them by -1 . The reason for this is that we wanted to align all the variables such that the higher variables represented a higher expected return. Each month we ranked the markets on two separate variables; for example, we ranked on momentum and the EP ratio, from the lowest to the highest. We then averaged both rankings and formed portfolios based on the combined ranking. The remainder of the procedure was identical to the portfolios that were based on single sorts.

When calculating the returns on portfolios, we aggregated the arithmetic returns in a cross-sectional fashion to form portfolios, and we subsequently converted them into log returns for statistical interfering.

\section{Performance Evaluation}

Examining multi-country international portfolios requires an appropriate asset pricing model. Such a model should comply with the perspectives of an international investor who is motivated to invest in foreign indices-based instruments (e.g., ETFs or futures contracts). In this paper, we used two models. To begin, we employed a country-level CAPM model (Sharpe, 1964). In this approach, which was proposed by Zaremba (2015a), the global market portfolio was composed of all the country portfolios in the sample weighted according to their capitalizations. Next, we attempted to consider other cross-sectional asset pricing effects, such as value, size, and momentum. However, we did not apply global stock-level asset pricing factors because this would be inconsistent with the assumption that investors allocate money to index-based vehicles. Conversely, we did not use country-level asset pricing factors such as Zaremba (2015a) has done, because it is irrational to test certain cross-national anomalies in pricing models where they are an integral component. Therefore, in addition to the country-level CAPM model, we determined whether the quantitative country selection strategies extend the frontier for a U.S. stock-level investor, and we took advantage of the four-factor model by Carhart (1997) based on the U.S. stock-level data. The stock-level data originated from the AQR data library (AQR, 2016).

In accordance with Fama and French (2012), all of the regression parameters were estimated using OLS regressions, which is consistent with the remarks of Cochrane (2005) who has regarded this method as more robust than GLS. Furthermore, $t$-statistics corresponding to each parameter were estimated using bootstrap standard errors to ensure that there was no distributional assumption. Moreover, to determine whether the intercepts of a group of portfolios statistically differ from 0 , they were evaluated with the common GRS test statistic, as suggested by Gibbons, Ross and Shanken 
(1989). The test's null hypothesis assumes that all the intercepts (five in total) are equal to 0 , with the alternative hypothesis assuming the contrary.

The GRS test for statistic weaknesses is an indication of the significant outperformance of certain portfolio sets, and it operates irrespective of the structure of the returns or their monotonicity. Therefore, to examine whether the excess returns (intercepts) are systematically increasing (for the EP and momentum) or decreasing (for skewness and turnover) in addition to the increase in the underlying variable, we also used the monotonic relation (MR) test introduced by Patton and Timmermann (2010). This test is a simulation-based test where the basic hypothesis is that there is no monotonic pattern in excess returns or intercepts (i.e., their values do not increase in addition to a decreasing variable), with an alternative hypothesis stating that such a pattern does exist. The precise testing procedure is described by Patton and Timmermann (2010). Each MR test in this paper was based on 10,000 random draws, and the test was applied to both raw excess returns and intercepts from factor models.

\section{Robustness Checks}

We performed a battery of robustness checks. First, we used two alternative weighting schemes: equal-weighting and liquidity weighting. As we noted previously, it is common in country-level studies to equal-weight the indices in portfolios (e.g., Asness et al., 2013). We used this approach to verify the robustness and to enable comparison with other studies that often also examine equally-weighted portfolios. Nonetheless, as we noted before, we were aware of this approach's disadvantages and potentially unrealistic assumptions. Second, occasionally, the capitalization-weighting approach may not fully reflect the varying level of liquidity across countries. This weakness is very important because many cross-sectional anomalies may stem from liquidity constraints (Jacobs, 2015; Pedersen, 2015). In fact, Novy-Marx and Velikov (2014) as well as Zaremba and Konieczka (2015) have argued that a precise adjustment for liquidity may seriously impede the profitability of certain strategies. Therefore, we also used a third weighting scheme: liquidity weighting. We used the average dollar turnover in months $t-12$ to $t-1$ as a proxy for stock market liquidity, and we weighted each of the countries accordingly.
Second, we re-examined all the strategies using gross returns (i.e., returns not adjusted for taxes on dividends). We used this approach because it is commonly employed in international studies; however, we found it to be less useful than the net approach. On the one hand, the net approach better reflects the investment practice. On the other hand, Zaremba and Konieczka (2016) have shown that returns on certain strategies, such as cross-country dividend yield investing, may become obliterated after adjusting for taxes on dividends. An important benefit of examining the strategies based on gross returns is that, in this case, we have access to older financial data. Consequently, the study period for this type of robustness check was lengthened to include data from May 1995-March 2015 (239 monthly observations).

Third, we used two different base currency conventions: euro (EUR) and Japanese yen (JPY). In other words, we performed all computations once again with the financial and market data converted to EUR and JPY. In these two cases, we detected no significant departure from our base USD outcomes; therefore, for brevity, we did not report the results of this robustness check in detail.

Fourth, it is common in cross-sectional studies to re-examine anomalies on the subsets of the full research period. However, in our case, the study period was relatively short; therefore, we eliminated this type of robustness check. Due to the limited availability of data, we did not investigate the earlier years to avoid small sample bias.

Fifth, we re-examined the performance of the strategies from double-sorts within sub-periods. We divided the research period into approximate halves (i.e., before December 31, 2006, and after this date). Next, to show that the performance in both sub-samples was not the result of specifically chosen cut-off dates, we also applied two alternative nearby dates as a basis for the division. The two dates selected were related to important market events: the Dow-Jones peak on October 11, 2007, and the Lehman Brothers bankruptcy on September 16, 2008.

Finally, we replicated the strategies formed from pairs of variables within emerging and developed markets. This check was additionally motivated by the observations of Harvey et al. (2004) and Dimic, Orlov and Piljak (2015), who have argued that the pricing 
Table 1. Excess Returns on Portfolios from Sorts on Single Variables

\begin{tabular}{|c|c|c|c|c|c|c|c|c|}
\hline & Low & 2 & 3 & 4 & High & $\mathrm{H}-\mathrm{L}$ & MR & GRS \\
\hline \multicolumn{9}{|c|}{ Earnings-to-price ratio } \\
\hline \multirow[t]{2}{*}{ Mean } & -0.15 & 0.40 & 0.80 & 0.27 & $1.12^{*}$ & $1.18^{* *}$ & 47.1 & \\
\hline & $(-0.35)$ & $(0.74)$ & $(1.47)$ & $(0.59)$ & $(1.93)$ & $(2.79)$ & & \\
\hline Volatility & 6.31 & 7.37 & 7.30 & 7.93 & 8.15 & 6.69 & & \\
\hline Sharpe ratio & -0.08 & 0.19 & 0.38 & 0.12 & 0.48 & 0.61 & & \\
\hline \multirow[t]{2}{*}{$a_{\text {CAPM }}$} & $-0.65^{* *}$ & -0.21 & 0.22 & -0.30 & 0.50 & $1.06^{* *}$ & 49.6 & 13.4 \\
\hline & $(-2.22)$ & $(-0.69)$ & $(0.69)$ & $(-0.72)$ & $(1.34)$ & (2.33) & & \\
\hline \multirow[t]{2}{*}{$a_{4 F}$} & -0.53 & 0.08 & 0.33 & -0.13 & 0.60 & $1.04^{* *}$ & 40.1 & 24.5 \\
\hline & $(-1.48)$ & $(0.19)$ & $(0.85)$ & $(-0.25)$ & $(1.33)$ & $(2.28)$ & & \\
\hline \multicolumn{9}{|c|}{ Momentum } \\
\hline \multirow[t]{2}{*}{ Mean } & 0.62 & 0.68 & 0.18 & 0.53 & 0.28 & -0.64 & 51.2 & \\
\hline & $(1.02)$ & $(1.26)$ & $(0.45)$ & $(1.11)$ & $(0.58)$ & $(-1.13)$ & & \\
\hline Volatility & 7.47 & 7.27 & 7.22 & 7.48 & 7.23 & 7.47 & & \\
\hline Sharpe ratio & 0.29 & 0.33 & 0.09 & 0.25 & 0.13 & -0.29 & & \\
\hline \multirow[t]{2}{*}{$a_{\text {CAPM }}$} & 0.10 & 0.11 & -0.33 & -0.07 & -0.29 & -0.67 & 44.1 & 89.5 \\
\hline & $(0.23)$ & $(0.43)$ & $(-0.89)$ & $(-0.16)$ & $(-0.83)$ & $(-1.21)$ & & \\
\hline \multirow[t]{2}{*}{$a_{4 F}$} & 0.32 & 0.32 & -0.23 & 0.05 & -0.14 & -0.76 & 58.8 & 84.8 \\
\hline & (0.85) & $(0.87)$ & $(-0.54)$ & $(0.13)$ & $(-0.31)$ & $(-1.43)$ & & \\
\hline \multicolumn{9}{|c|}{ Turnover ratio } \\
\hline \multirow[t]{2}{*}{ Mean } & 0.76 & 0.35 & 0.37 & 0.55 & -0.08 & $-1.10^{* * *}$ & 29.8 & \\
\hline & (1.43) & $(0.79)$ & $(0.73)$ & $(1.55)$ & $(-0.08)$ & $(-2.89)$ & & \\
\hline Volatility & 7.31 & 6.59 & 7.16 & 5.04 & 5.35 & 5.17 & & \\
\hline Sharpe ratio & 0.36 & 0.18 & 0.18 & 0.38 & -0.05 & -0.74 & & \\
\hline \multirow[t]{2}{*}{$a_{\text {CAPM }}$} & 0.02 & -0.14 & -0.16 & 0.16 & $-0.47^{*}$ & $-0.75^{* * *}$ & 71.5 & 3.7 \\
\hline & $(0.77)$ & $(-0.37)$ & $(-0.40)$ & $(0.69)$ & $(-1.70)$ & $(-2.65)$ & & \\
\hline \multirow[t]{2}{*}{$a_{4 F}$} & 0.3 & -0.02 & 0 & 0.23 & $-0.37^{* *}$ & $-0.94^{* *}$ & 46.0 & 3.3 \\
\hline & $(0.81)$ & $(-0.07)$ & $(0.01)$ & (1.34) & $(-2.42)$ & $(-2.52)$ & & \\
\hline \multicolumn{9}{|c|}{ Skewness } \\
\hline \multirow[t]{2}{*}{ Mean } & $1.52^{* * *}$ & 0.30 & 0.14 & 0.66 & 0.54 & $-1.17^{* *}$ & 56.5 & \\
\hline & (2.99) & $(0.58)$ & (0.39) & $(1.17)$ & $(1.04)$ & $(-2.42)$ & & \\
\hline Volatility & 6.65 & 7.48 & 7.20 & 8.19 & 7.38 & 6.69 & & \\
\hline Sharpe ratio & 0.79 & 0.14 & 0.07 & 0.28 & 0.25 & -0.61 & & \\
\hline \multirow[t]{2}{*}{$a_{\text {CAPM }}$} & $0.96^{* * *}$ & -0.28 & -0.42 & 0.02 & -0.04 & $-1.18^{* *}$ & 46.4 & 0.5 \\
\hline & $(3.57)$ & $(-0.77)$ & $(-1.33)$ & $(0.09)$ & $(-0.13)$ & $(-2.55)$ & & \\
\hline \multirow[t]{2}{*}{$a_{4 F}$} & $1.20 * * *$ & -0.18 & -0.24 & 0.30 & 0.08 & $-1.31^{* * *}$ & 54.4 & 0.1 \\
\hline & (3.48) & $(-0.44)$ & $(-0.71)$ & $(0.66)$ & $(0.21)$ & $(-2.81)$ & & \\
\hline
\end{tabular}

Note. This table reports the means, standard deviations, Sharpe ratios, and intercepts from the CAPM and the four-factor model of excess net returns on quintile capitalization-weighted portfolios sorted by the earnings-to-price ratio, the momentum, the turnover ratio, and the skewness. "Low" denotes markets with the lowest variable, and "High" denotes markets with the highest variable. "H-L" (high minus low) is a zero-cost portfolio that is long in the high-variable markets and short in the low-variable markets. MR and GRS are p-ᄀvalues from MR (Patton \& Timmermann, 2010) and GRS (Gibbons et al., 1989) tests. The means, standard deviations, intercepts, and p-values are expressed as percentages. The numbers in brackets are t-statistics based on bootstrap standard errors, and the significance at the $10 \%$ level is in bold characters. ${ }^{* * *}$, and ${ }^{* * *}$ indicate values that are significantly different from 0 at the 10\%,5\%, and 1\% levels, respectively. The Sharpe ratios are based on annualized data. 
relationship may be different in developed and emerging markets. In this test, in accordance with the MSCI approach, we also consider the dynamic classification changes. We assigned markets to the developed markets category in month $t$ when they were classified in this way in a given period of MSCI (see MSCI (2015)). All of the remaining markets (i.e., those classified by MSCI as emerging, frontier, or stand-alone) were categorized in month $t$ as emerging markets.

\section{Results and Discussion}

This section presents the results of our research. First, we re-examined the strategies from single sorts. Next, we investigated the portfolios based on merged rankings and determined whether they outperformed the single-variable portfolios.

Table 1 presents the performance of portfolios from sorts on single metrics: the EP ratio, momentum, the turnover ratio, and skewness. Three of these indicators were found to be potentially important for international investors: the EP ratio, the turnover ratio, and skewness. In each of these cases, the average return on a zero-portfolio had a sign that is consistent with our expectations, and it is significantly different than 0 . The absolute monthly mean returns for all of these metrics exceeded $1 \%$, and the abnormal returns were not fully explained by either the global CAPM or the U.S. fourfactor model. Consequently, the intercepts from these models were positive and significantly different than 0 . The absolute CAPM alphas varied from $0.75 \%$ for the turnover ratio to $1.18 \%$ for skewness. The absolute four-factor alphas were $1.04 \%, 0.94 \%$ and $1.31 \%$ for the long/short portfolios from sorts on the EP ratio, the turnover ratio, and skewness, respectively. The Sharpe ratios for the zero-portfolios were relatively large in absolute terms, 0.61 for the EP ratio and skewness and -0.74 for the turnover ratio. Naturally, the low Sharpe ratio for the zero portfolio (the intercepts and mean returns as well) was not a problem, because an investor can easily build an identical short version of this by simply shorting the liquid markets and going long in the illiquid markets. The reason why the last strategy outperformed the others in terms of Sharpe ratios is because of its lower volatility. The standard deviation of monthly excess returns was $5.17 \%$, which was lower than the other two country selection methods. Interestingly, the GRS tests suggested no significant expan- sion of the efficient frontier for the EP ratio. The GRS hypothesis was only rejected for portfolios from sorts on skewness and the turnover ratio.

Although in each of the three above-described cases the top portfolio outperformed the bottom portfolio, the general cross-sectional pattern of returns was uneven and far from linear. In fact, the null hypothesis was rejected for none of the metrics investigated by the MR test. In other words, we did detected no vivid monotonicity in excess returns on portfolios based on ranked country indices. The abnormal performance of a zero-portfolio apparently stemmed from the returns on the market with extreme underlying metrics. For example, the turnover ratios were the most liquid markets that had particularly large negative abnormal returns. Conversely, in the case of skewness, the superior performance of the long/short portfolios was mainly driven by impressive returns in the country equity markets with the most left-skewed past-return distributions.

Our investigation of portfolios from sorts on the three described indicators were in accordance with the previous findings. We confirmed that ranking stocks based on the EP ratio, the turnover ratio, and skewness may be helpful when designing profitable countryselection strategies.

Finally, the fourth anomaly that we examined, the inter-market momentum, was the most disappointing for international investors. Similar to Zaremba and Konieczka (2016), we found that momentum is not a suitable basis for building country-level capitalizationweighted portfolios. The GRS and the MR tests' hypotheses were not rejected, and the excess returns on zero-portfolios displayed no abnormal performance. Zaremba and Konieczka (2016) have argued that the reason for the poor performance of such countrylevel momentum portfolios may lie in the weighting scheme. Zaremba (2015a) as well as Zaremba and Konieczka (2016) have shown that the country-level momentum effect is strongest within small markets. Consequently, if the weighting scheme emphasizes the large markets with the lowest or negative momentum returns, the overall performance of the strategy may also be poor.

The returns on the country-level factor strategies examined in this study were not strongly correlated with each other (Table 2). The long-only and short- 
Table 2. Correlation Coefficients for Country-Level Strategies Based on a Single Sorting Variable

\begin{tabular}{|c|c|c|c|c|c|c|c|c|c|}
\hline & \multicolumn{3}{|c|}{ Long leg } & \multicolumn{3}{|c|}{ Short leg } & \multicolumn{3}{|c|}{ Long minus short } \\
\hline & Mom & TR & Skew & Mom & $\mathrm{TR}$ & Skew & Mom & $\mathrm{TR}$ & Skew \\
\hline \multirow[t]{2}{*}{ EP } & $0.65^{* * *}$ & $0.60^{* * *}$ & $0.72^{* * *}$ & $0.64^{* * *}$ & $0.64^{* * *}$ & $0.68^{* * *}$ & 0.05 & -0.08 & 0.10 \\
\hline & (11.91) & (10.39) & $(14.36)$ & (11.49) & (11.48) & $(12.72)$ & $(0.63)$ & $(-1.13)$ & $(1.45)$ \\
\hline \multirow[t]{2}{*}{ Mom } & & $0.57^{* * *}$ & $0.76^{* * *}$ & & $0.61^{* * *}$ & $0.61^{* * *}$ & & $-0.28^{* * *}$ & -0.12 \\
\hline & & (9.61) & (16.21) & & (10.63) & (10.70) & & $(-4.04)$ & $(-1.64)$ \\
\hline \multirow[t]{2}{*}{ TR } & & & $0.81 * * *$ & & & $0.59 * * *$ & & & $-0.16^{* *}$ \\
\hline & & & (19.35) & & & (10.04) & & & $(-2.29)$ \\
\hline
\end{tabular}

Note. This table reports the correlation coefficients of the return on portfolios from sorts on the earnings-to-price ratio ("EP"), the momentum ("Mom"), the reverse turnover ratio ("TR"), and the reverse skewness ("Skew"). The numbers in brackets are t-statistics based on bootstrap standard errors, and the significance at the $10 \%$ level is in bold characters. ${ }^{*},{ }^{* *}$, and ${ }^{* * *}$ indicate values that are significantly different from 0 at the 10\%,5\%, and 1\% levels, respectively. This table reports the correlation coefficients for top-quintile portfolios ("Long leg"), bottom quintile portfolios ("Short leg"), and top-minus-bottom long/short portfolios ("Long minus short").

only portfolios naturally revealed correlation (correlation coefficients in a range of $0.57-0.72$ ), but this was mainly due to a common market risk factor. When we considered the zero-portfolios, the correlations were predominantly close to 0 . Moreover, the returns on the turnover ratio strategy were negatively correlated with the returns on zero-portfolios formed on skewness and momentum. The absolute values of the coefficients were low ( -0.16 and -0.28 respectively), but they were significantly different than 0 . Interestingly, we found no significant correlation between momentum and the EP ratio strategy. This observation to an extent contradicted the main conclusions of Asness et al. (2013) who have examined value and momentum strategies across a broad range of asset classes and have found that their returns are usually negatively correlated. Nonetheless, these authors have tested equally weighted portfolios within a sample of 18 country equity indices. Therefore, the discrepancies may simply stem from differences in sample size and methodology.

The low correlation among the strategies examined here is particularly important for global investors. This low correlation clearly indicates that it would be beneficial to form a portfolio of various country-level strategies. The low correlation would help to mitigate risk by diversification and reduce the volatility of the returns. In summary, the results show that reasonable investors should build portfolios with strategies from single sorts to maximize the return-to-risk ratio of their investments.

Table 3 shows the performance of strategies from single sorts with alternative return computation conventions and weighting schemes. For brevity, we presented only the characteristics of zero-portfolios and the corresponding MR tests' $p$-values. Not all the strategies appeared equally robust to the changes we observed. The two most robust strategies were based on skewness and the EP ratio; this was consistent with the previous work of Zaremba and Konieczka (2016) and Zaremba and Nowak (2015). The raw and abnormal returns on country portfolios from sorts on the EP ratio were consistent with our expectations, and they were significantly different than 0 for nearly all variants. The sole exception was the equally weighted portfolio based on gross returns. In this case, the alphas and the returns remained consistent with the expectations, but they were not statistically significant.

The portfolios from sorts on skewness were characterized by similar performance in all the specifications. With the exception of equal-weighting, all of the remaining weighting schemes had negative and significant intercepts from factor models and raw returns.

For both strategies described, the Sharpe ratios of alternative weights were relatively high in absolute 
Table 3. Excess Returns on Portfolios from Sorts on Single Variables: Alternative Weighting Schemes and Return Conventions

\begin{tabular}{|c|c|c|c|c|c|c|c|c|c|c|}
\hline & \multicolumn{2}{|c|}{$\begin{array}{l}\text { Equally weighted } \\
\text { portfolios (gross } \\
\text { returns) }\end{array}$} & \multicolumn{2}{|c|}{$\begin{array}{c}\text { Equally weighted } \\
\text { portfolios (net } \\
\text { returns) }\end{array}$} & \multicolumn{2}{|c|}{$\begin{array}{c}\text { Capitalization- } \\
\text { weighted } \\
\text { portfolios (gross } \\
\text { returns) }\end{array}$} & \multicolumn{2}{|c|}{$\begin{array}{l}\text { Liquidity-weighted } \\
\text { portfolios (gross } \\
\text { returns) }\end{array}$} & \multicolumn{2}{|c|}{$\begin{array}{l}\text { Liquidity weighted } \\
\text { portfolios (net } \\
\text { returns) }\end{array}$} \\
\hline & $\mathrm{H}-\mathrm{L}$ & MR & $\mathrm{H}-\mathrm{L}$ & $M R$ & $\mathrm{H}-\mathrm{L}$ & MR & $\mathrm{H}-\mathrm{L}$ & $M R$ & $\mathrm{H}-\mathrm{L}$ & MR \\
\hline \multicolumn{11}{|c|}{ Earnings-to-price ratio } \\
\hline Mean & 0.34 & 8.5 & $0.48^{*}$ & 0.7 & $1.04^{* *}$ & 37.6 & $1.00 * * *$ & 2.1 & $0.75^{* * *}$ & 11.2 \\
\hline$a_{\text {CAPM }}$ & 0.31 & 15.1 & $0.42^{*}$ & 1.5 & $0.99 * *$ & 40.1 & $0.93^{* *}$ & 5.6 & $0.60^{* *}$ & 35.4 \\
\hline$a_{4 F}$ & 0.26 & 21.7 & 0.40 & 0.2 & $0.89 * *$ & 41.3 & $0.87^{* *}$ & 22.9 & $0.64^{* *}$ & 37.3 \\
\hline Sharpe ratio & 0.30 & & 0.46 & & 0.50 & & 0.59 & & 0.60 & \\
\hline \multicolumn{11}{|c|}{ Momentum } \\
\hline Mean & $0.67^{* * *}$ & 0.0 & $0.47^{* *}$ & 19.1 & -0.39 & 34.2 & 0.38 & 1.9 & -0.06 & 44.4 \\
\hline$a_{\text {CAPM }}$ & $0.71^{* *}$ & 0.0 & $0.53^{*}$ & 6.0 & -0.39 & 36.4 & 0.40 & 3.2 & -0.09 & 27.3 \\
\hline$a_{4 F}$ & $0.55^{*}$ & 0.4 & 0.37 & 37.2 & -0.61 & 33.3 & 0.08 & 8.5 & -0.24 & 65.4 \\
\hline Sharpe ratio & 0.50 & & 0.37 & & -0.17 & & 0.22 & & -0.04 & \\
\hline \multicolumn{11}{|c|}{ Turnover ratio } \\
\hline Mean & -0.44 & 77.6 & $-0.79 * *$ & 1.5 & -0.59 & 35.8 & -0.06 & 89.3 & -0.50 & 23.7 \\
\hline$a_{\text {CAPM }}$ & -0.31 & 84.0 & $-0.65^{*}$ & 7.7 & -0.34 & 6.2 & -0.05 & 95.4 & -0.38 & 43.8 \\
\hline$a_{4 F}$ & -0.55 & 69.1 & $-0.81^{* *}$ & 3.7 & -0.56 & 27.1 & -0.07 & 90.4 & -0.40 & 27.3 \\
\hline Sharpe ratio & -0.29 & & -0.56 & & -0.38 & & -0.04 & & -0.41 & \\
\hline \multicolumn{11}{|c|}{ Skewness } \\
\hline Mean & $-0.39^{*}$ & 46.4 & $-0.42^{* *}$ & 5.5 & $-1.45^{* * *}$ & 11.5 & $-0.99 * * *$ & 7.3 & $-0.74^{* *}$ & 12.6 \\
\hline$a_{\text {CAPM }}$ & -0.36 & 70.1 & -0.38 & 7.4 & $-1.48^{* * *}$ & 3.7 & $-1.03^{* * *}$ & 5.0 & $-0.74^{* *}$ & 12.4 \\
\hline$a_{4 F}$ & -0.25 & 84.6 & -0.34 & 14.0 & $-1.43^{* * *}$ & 13.8 & $-1.01^{* * *}$ & 4.6 & $-0.80^{* * *}$ & 12.4 \\
\hline Sharpe ratio & -0.40 & & -0.44 & & -0.73 & & -0.86 & & -0.64 & \\
\hline
\end{tabular}

Note. This table reports the means, Sharpe ratios, and the intercepts from the CAPM and the four-factor model of excess returns on quintile portfolios sorted by the earnings-to-price ratio, the momentum, the turnover ratio, and the skewness. "H-L" (high minus low) is a zero-cost portfolio that is long in the high-variable markets and short in the low-variable markets. MR and $p$ - $\neg$ values are from the MR test (Patton \& Timmermann, 2010). The means, intercepts, and p-values are expressed as percentages. The numbers in brackets are t-statistics based on bootstrap standard errors, and the significance at the 10\% level is in bold characters. ${ }^{*},{ }^{* *}$, and ${ }^{* * *}$ indicate values that are significantly different from 0 at the $10 \%, 5 \%$, and $1 \%$ levels, respectively. The Sharpe ratios are based on annualized data.

terms, although they were markedly lower for equalweighting schemes than for capitalization-weighting schemes. Interestingly, the portfolios from sorts on the EP ratio and skewness displayed a degree of monotonicity in their returns. The evidence was not very strong, but it was nonetheless notable. The null hypotheses of the MR tests were rejected for nearly half of the intercepts and returns we examined (i.e., monotonicity was detected).
The case of momentum appeared particularly interesting. Although the country-level momentum was extensively documented in the literature, it appeared to work well only for equally weighted portfolios. When the gross returns on equal-weighted portfolios were considered, we found very high and significant returns and alphas for the zero-portfolio. Furthermore, the MR tests indicated vivid monotonicity in returns. However, when we considered alternative weighting 
Table 4. Excess Returns on Portfolios from Sorts on Combined Pairs of Variables

Panel A: The earnings-to-price ratio and momentum, the earnings-to-price ratio and the turnover ratio, the earnings-to-price ratio and skewness, and the momentum and the turnover ratio

\begin{tabular}{|c|c|c|c|c|c|c|c|c|}
\hline & Low & 2 & 3 & 4 & High & $\mathrm{H}-\mathrm{L}$ & MR & GRS \\
\hline \multicolumn{9}{|c|}{ Earnings-to-price ratio \& momentum } \\
\hline \multirow[t]{2}{*}{ Mean } & 0.12 & -0.12 & 0.57 & 0.47 & $0.89 *$ & 0.61 & 12.5 & \\
\hline & $(0.20)$ & $(-0.21)$ & $(1.11)$ & $(0.91)$ & $(1.86)$ & $(1.61)$ & & \\
\hline Volatility & 6.53 & 7.14 & 7.58 & 7.48 & 7.66 & 6.98 & & \\
\hline Sharpe ratio & 0.06 & -0.06 & 0.26 & 0.22 & 0.40 & 0.30 & & \\
\hline \multirow[t]{2}{*}{$a_{\text {CAPM }}$} & -0.41 & -0.67 & 0.02 & -0.08 & 0.32 & 0.58 & 17.2 & 23.6 \\
\hline & $(-1.40)$ & $(-2.00)$ & $(0.06)$ & $(-0.19)$ & $(0.89)$ & $(1.19)$ & & \\
\hline \multirow[t]{2}{*}{$a_{4 F}$} & -0.21 & -0.51 & 0.19 & 0.02 & 0.37 & 0.43 & 24.2 & 55.0 \\
\hline & $(-0.52)$ & $(-1.45)$ & $(0.37)$ & $(0.10)$ & (0.93) & $(0.86)$ & & \\
\hline \multicolumn{9}{|c|}{ Earnings-to-price ratio \& turnover ratio } \\
\hline \multirow[t]{2}{*}{ Mean } & 0.00 & 0.48 & -0.01 & 0.28 & $1.25^{* *}$ & $1.26^{* * *}$ & 58.6 & \\
\hline & $(0.11)$ & $(1.19)$ & $(0.04)$ & $(0.41)$ & $(2.05)$ & $(2.67)$ & & \\
\hline Volatility & 5.27 & 6.09 & 6.60 & 8.53 & 8.43 & 6.51 & & \\
\hline Sharpe ratio & 0.00 & 0.27 & -0.01 & 0.11 & 0.51 & 0.67 & & \\
\hline \multirow[t]{2}{*}{$a_{\text {CAPM }}$} & -0.39 & 0.02 & -0.49 & -0.44 & $0.47^{*}$ & $0.86^{* *}$ & 73.8 & 17.2 \\
\hline & $(-1.44)$ & $(0.11)$ & $(-1.51)$ & $(-1.22)$ & (1.84) & (2.19) & & \\
\hline \multirow{2}{*}{$a_{4 F}$} & $-0.31^{*}$ & 0.2 & -0.37 & -0.16 & $0.78^{*}$ & $1.09 * * *$ & 74.4 & 2.8 \\
\hline & $(-2.14)$ & $(0.79)$ & $(-1.06)$ & $(-0.34)$ & $(1.84)$ & $(2.60)$ & & \\
\hline \multicolumn{9}{|c|}{ Earnings-to-price ratio \& skewness } \\
\hline \multirow[t]{2}{*}{ Mean } & -0.05 & 0.48 & 0.50 & 0.83 & $1.06 * *$ & $0.95^{* *}$ & 0.3 & \\
\hline & $(-0.14)$ & $(1.01)$ & $(1.06)$ & (1.48) & (1.96) & $(2.04)$ & & \\
\hline Volatility & 6.64 & 6.93 & 7.96 & 7.52 & 7.32 & 6.46 & & \\
\hline Sharpe ratio & -0.03 & 0.24 & 0.22 & 0.38 & 0.50 & 0.51 & & \\
\hline \multirow[t]{2}{*}{$a_{C A P M}$} & $-0.57^{*}$ & -0.05 & -0.14 & 0.26 & 0.5 & $0.92^{* *}$ & 2.8 & 20.6 \\
\hline & $(-1.78)$ & $(-0.17)$ & $(-0.30)$ & $(0.74)$ & $(1.47)$ & $(2.17)$ & & \\
\hline \multirow[t]{2}{*}{$a_{4 F}$} & -0.43 & 0.14 & 0.11 & 0.31 & 0.63 & $0.90^{* *}$ & 1.6 & 29.8 \\
\hline & $(-1.14)$ & $(0.43)$ & $(0.24)$ & $(0.77)$ & (1.59) & $(2.03)$ & & \\
\hline \multicolumn{9}{|c|}{ Momentum \& turnover ratio } \\
\hline \multirow[t]{2}{*}{ Mean } & -0.05 & 0.70 & 0.60 & 0.15 & 0.74 & $0.75^{*}$ & 48.0 & \\
\hline & $(-0.02)$ & $(1.29)$ & $(1.24)$ & $(0.33)$ & (1.48) & $(1.95)$ & & \\
\hline Volatility & 5.88 & 7.37 & 6.45 & 7.13 & 7.85 & 5.67 & & \\
\hline Sharpe ratio & -0.03 & 0.33 & 0.32 & 0.08 & 0.33 & 0.46 & & \\
\hline \multirow[t]{2}{*}{$a_{\text {CAPM }}$} & -0.46 & 0.16 & 0.1 & -0.4 & 0.03 & 0.47 & 63.9 & 35.4 \\
\hline & $(-1.47)$ & $(0.43)$ & $(0.39)$ & $(-1.18)$ & $(0.21)$ & $(1.45)$ & & \\
\hline \multirow[t]{2}{*}{$a_{4 F}$} & -0.36 & 0.38 & 0.24 & -0.28 & 0.27 & 0.6 & 62.3 & 20.5 \\
\hline & $(-1.61)$ & $(1.09)$ & $(0.75)$ & $(-0.77)$ & $(0.73)$ & (1.52) & & \\
\hline
\end{tabular}


Panel B: Momentum and skewness, and the turnover ratio and skewness

\begin{tabular}{|c|c|c|c|c|c|c|c|c|}
\hline & Low & 2 & 3 & 4 & High & $\mathrm{H}-\mathrm{L}$ & MR & GRS \\
\hline \multicolumn{9}{|c|}{ Momentum \& skewness } \\
\hline \multirow[t]{2}{*}{ Mean } & 0.06 & 0.08 & 0.64 & 0.66 & 0.70 & 0.41 & 0.5 & \\
\hline & $(0.08)$ & $(0.14)$ & (1.56) & $(1.21)$ & $(1.34)$ & (0.79) & & \\
\hline Volatility & 7.43 & 7.41 & 6.11 & 7.14 & 7.33 & 6.73 & & \\
\hline Sharpe ratio & 0.03 & 0.04 & 0.36 & 0.32 & 0.33 & 0.21 & & \\
\hline \multirow[t]{2}{*}{$a_{C A P M}$} & -0.49 & -0.48 & 0.2 & 0.09 & 0.1 & 0.37 & 4.8 & 42.0 \\
\hline & $(-1.29)$ & $(-1.33)$ & $(0.68)$ & $(0.23)$ & (0.43) & (0.84) & & \\
\hline \multirow[t]{2}{*}{$a_{4 F}$} & -0.35 & -0.32 & 0.32 & 0.3 & 0.21 & 0.33 & 3.9 & 45.3 \\
\hline & $(-0.78)$ & $(-0.84)$ & $(0.98)$ & $(0.77)$ & $(0.56)$ & $(0.71)$ & & \\
\hline \multicolumn{9}{|c|}{ Turnover ratio \& skewness } \\
\hline \multirow[t]{2}{*}{ Mean } & -0.28 & 0.09 & $0.87^{* *}$ & 0.49 & 0.98 & $1.21^{* *}$ & 36.0 & \\
\hline & $(-0.51)$ & $(0.28)$ & (1.99) & (0.86) & $(1.61)$ & (2.51) & & \\
\hline Volatility & 6.11 & 6.53 & 6.29 & 8.52 & 8.04 & 6.04 & & \\
\hline Sharpe ratio & -0.16 & 0.05 & 0.48 & 0.20 & 0.42 & 0.70 & & \\
\hline \multirow[t]{2}{*}{$a_{\text {CAPM }}$} & $-0.74 * *$ & -0.38 & 0.41 & -0.16 & 0.23 & $0.91^{* *}$ & 71.6 & 3.7 \\
\hline & $(-2.36)$ & $(-1.12)$ & $(1.37)$ & $(-0.39)$ & $(1.07)$ & (2.37) & & \\
\hline \multirow[t]{2}{*}{$a_{4 F}$} & $-0.63^{* *}$ & -0.3 & 0.44 & 0.09 & 0.54 & $1.12^{* * *}$ & 33.3 & 2.3 \\
\hline & $(-2.48)$ & $(-0.91)$ & (1.34) & (0.23) & $(1.31)$ & (2.64) & & \\
\hline
\end{tabular}

Note. This table reports the means, standard deviations, Sharpe ratios, and intercepts from the CAPM and the four-factor model of excess net returns on quintile capitalization-weighted portfolios sorted in pairs of the following variables: the earningsto-price ratio, the momentum, the reverse turnover ratio (the turnover ratio multiplied by -1), and the reverse skewness (the skewness multiplied by -1). The markets are ranked according to two separate variables, and the portfolios are formed based on the sum of ranks in both rankings. "Low" denotes markets with the lowest variables, and "High" denotes markets with the highest variables. "H-L" (high minus low) is a zero-cost portfolio that is long in the high-rank markets and short in the low-rank markets. MR and GRS are p-ᄀvalues derived from MR (Patton \& Timmermann, 2010) and GRS (Gibbons et al., 1989) tests. The means, standard deviations, intercepts, and p-values are expressed as percentages. The numbers in brackets are t-statistics based on bootstrap standard errors, and the significance at the $10 \%$ level is in bold characters. ${ }^{*}$,*, and ${ }^{* * *}$ indicate values that are significantly different from 0 at the 10\%,5\%, and 1\% levels, respectively. The Sharpe ratios are based on annualized data.

schemes, the positive abnormal returns disappeared and in certain cases became negative (although not significantly different than 0 ). Thus, our outcomes were similar to Zaremba and Konieczka (2016).

The strategy based on the turnover ratio ranks best for equal-weighted portfolios when net returns were considered. For capitalization- and equal-weighted portfolios that were based on gross returns, the alphas remained negative (but they were no longer significantly different than 0 ), and the Sharpe ratios were markedly decreased. Moreover, the returns on zero- portfolio portfolios nearly disappeared completely when the returns were liquidity-weighted. This observation was similar to Zaremba and Konieczka (2016). The underlying reason for this could be that the source of return for the turnover-based strategy stems from markets that are less liquid. In fact, the turnover-based weighting scheme minimized its influence on portfolio performance and overemphasized liquid markets, which perform the weakest.

Table 4 presents the performance of strategies from sorts on pairs of variables. The portfolios based on av- 
eraged rankings of momentum and the EP ratio did not reveal a significant cross-sectional pattern. The zero-portfolios were not characterized by significant abnormal returns, and the MR and GRS tests' $p$-values strongly exceeded $10 \%$. Again, our results in this case were different than those of Asness et al. (2013). However, this finding is not extremely astonishing because the momentum itself was an unprofitable strategy.

The zero-portfolios from sorts on the EP ratio and the turnover ratio performed very well. The mean monthly return was $1.26 \%$, and the intercepts from the global CAPM and U.S. four-factor models were $0.86 \%$ and $1.09 \%$, respectively (all the numbers were significantly different than 0 ). The abnormal returns were largely driven by the great performance of the top-ranked markets. Finally, the MR test suggested no monotonicity. In other words, the results appeared to be due to the impressive performance in extreme markets rather than in a stable monotonic cross-sectional pattern.

The performance of portfolios from simultaneous sorts on the EP ratio and skewness was also remarkable. Not only were all intercepts on zero-portfolios positive and significantly different than 0 , the MR test clearly suggested the monotonicity of the returns. However, the GRS tests were not rejected.

The strategy based on momentum and the turnover ratio did not prove to be very useful for investors. Although the raw returns on the long/short portfolios were, on average, positive and significantly different than 0 , the abnormal performance here is explained by the asset pricing models employed by this study. When we explain the global market risk or U.S. value, the size and momentum effect of the alphas were no longer significantly different than 0 . Furthermore, the MR and the GRS tests' hypotheses were not rejected in any of these cases.

The performance of strategies based on momentum and skewness was also unsatisfactory. Although the high-ranked countries appeared to perform somewhat better than the low-ranked countries (with higher returns and intercepts from the asset pricing models), the scale of outperformance was low and insignificant. Although the MR test suggested monotonicity in the returns, the GRS tests were not rejected.

Finally, the portfolios derived from sorts on combined rankings according to the turnover ratio and skewness appeared to pose a very attractive strategy. The top markets outperformed the bottom markets, and the returns on the long/short portfolios were, on average, $1.21 \%$ per month. The intercepts from the asset pricing model were significant and positive, ranging from $0.91 \%$ to $1.12 \%$. Although the MR test's $p$ values indicate no monotonicity, which confirmed the initial suppositions that the abnormal returns originated from markets with extreme underlying metrics, both the GRS tests related to the CAPM and the four-factor model indicated a significant shift in the efficient frontier.

A review of the six strategies from double-sorts reported in Table 4 led to two interesting conclusions. First, the rankings that used momentum as one of the sorting variables did not perform very well. None of the examined variances produced significant and positive intercepts from factor models apparently because the momentum strategy works poorly for capitalization-weighted portfolios. Second, although the performance of the remaining strategies was remarkable, the performance does not appear to be superior to the strategies from the sorts on single variables. For example, the Sharpe ratio of the zero-portfolios was often higher than for both zero-investment portfolios based on the constituent strategies than for the composite strategy. In each case, one of these strategies actually performed better. This thesis holds even if we use CAPM or the four-factor model alpha as a measure of abnormal performance. As always, one the constituent strategies performed better. This observation cast doubt concerning the validity of building portfolios based on averaged rankings. If the underlying strategies performed better on a stand-alone basis, it appears more reasonable to build a portfolio of strategies that is based on single variables rather than to blend two variables into one strategy. This argument may be particularly important; given the results in Table 2, strategies from single sorts were not correlated with each other. In a portfolio, it would be possible to diversify away a portion of the volatility.

To further test the robustness of the results reported in Table 4, we re-examined the performance of the six portfolios with cross-sectional and time-series subsamples (i.e., within developed and emerging markets, see Table A1 in the appendix) and with the earlier and latter halves of the sample (see Table A2 in the appen- 
dix). Basically, these tests confirmed the profitability of the strategies examined; the zero-investment portfolios delivered predominantly positive returns within the sub-samples. Nevertheless, in accordance with the observations of Harvey (2004), we observed that the pricing relationship was generally stronger within the emerging markets. Furthermore, the returns were visibly lower within the latter sub-periods of the main sample. The underlying source of this time-series variation could be explored in future studies.

Table 5 describes the performance of portfolios based on the average ranking of two variables that used alternative weighting-schemes and return conventions. Two combinations appeared particularly convincing: the EP ratio with skewness and the turnover ratio with skewness. In this variant, most of the mean raw returns and intercepts from asset pricing models were positive and significantly different than 0 . Moreover, in many cases, the MR tests strongly confirmed the monotonic cross-sectional patterns in the sets of portfolios that were examined. Furthermore, particular combinations were characterized by exceptionally high Sharpe ratios. For example, the Sharpe ratio of the equally weighted portfolio from simultaneous sorts on the turnover ratio and skewness (i.e., the net return convention) was 0.88 , which was greater than any of the strategies from single sorts. Nonetheless, considering the entire set of robustness tests, we found no strong evidence that sorting simultaneously on two cross-sectional strategies leads to a significant improvement in performance. Basically, the levels of the Sharpe ratios and the alphas in Tables 4 and 5 were similar to those in Tables 1 and 3 and revealed no significant improvement. In other words, the examination of the outcomes in Table 5 confirmed the conclusions from Table 4.

The results of the final mean-variance spanning tests are presented in Table 6. Basically, the outcomes suggest that strategies based on pairs of variables do not perform better than strategies based on single variables. When we consider our base approach, net returns on capitalization-weighted portfolios, none of the strategies from simultaneous sorts on two variables significantly augmented the efficient frontier made by the two separate underlying strategies. The intercepts are occasionally positive and occasionally negative; however, in none of the cases were they significantly different from 0. Furthermore, the investigation of portfolios with alternative weighting schemes and tests based on gross returns do not alter the overall picture. With a few exceptions, most of the intercepts did not differ significantly from 0 , and no significant pattern could be detected for any of the combinations. In other words, combining two strategies into one does not lead to much improvement in performance when compared with separate component strategies. In fact, given the very low or negative correlation among the strategies examined in this study, investors would be better off building a portfolio of separate component strategies than blending them into one unified strategy.

\section{Concluding Remarks}

The research presented investigated the performance of blended country-level quantitative strategies. Among the re-examined strategies from sorts on single variables, we found that three strategies proved to be useful tools for international investors; these were the strategies based on the EP ratio, the turnover ratio, and skewness. Furthermore, strategies based on the combined rankings of the EP ratio with skewness and the turnover ratio with skewness were also characterized by attractive alphas and Sharpe ratios. However, the blended strategies did not outperform the portfolios based on single metrics. Consequently, we argue that, given the low correlation among the returns on single-variable strategies, investors would be better off building a diversified portfolio of independent strategies rather than blending them into a single approach. These observations are important for fund pickers and money managers who have a global investment mandate.

Our study has two limitations of potentially large importance. First, we did not consider transaction costs, and Novy-Marx and Velikov (2014) as well as Zaremba and Konieczka (2015) have shown that these costs can be potentially harmful for certain crosssectional strategies. Second, our study period encompassed the global financial crisis. This important global event may have influenced the results in an unexpected manner.

Future studies on the issues discussed in this paper should further explore the properties of the strategies examined. Such research could be pursued in several directions. First, one of the disadvantages of the 
Table 5. Excess Returns on Portfolios from Sorts on Combined Pairs of Variables: Alternative Weighting Schemes and Return Conventions

\begin{tabular}{|c|c|c|c|c|c|c|c|c|c|c|}
\hline & \multicolumn{2}{|c|}{$\begin{array}{c}\text { Equally weighted } \\
\text { portfolios (gross } \\
\text { returns) }\end{array}$} & \multicolumn{2}{|c|}{$\begin{array}{l}\text { Equally weighted } \\
\text { portfolios (net } \\
\text { returns) }\end{array}$} & \multicolumn{2}{|c|}{$\begin{array}{c}\text { Capitalization- } \\
\text { weighted } \\
\text { portfolios (gross } \\
\text { returns) } \\
\end{array}$} & \multicolumn{2}{|c|}{$\begin{array}{l}\text { Liquidity-weighted } \\
\text { portfolios (gross } \\
\text { returns) }\end{array}$} & \multicolumn{2}{|c|}{$\begin{array}{l}\text { Liquidity weighted } \\
\text { portfolios (net } \\
\text { returns) }\end{array}$} \\
\hline & $\mathrm{H}-\mathrm{L}$ & $M R$ & $\mathrm{H}-\mathrm{L}$ & $M R$ & $\mathrm{H}-\mathrm{L}$ & $M R$ & $\mathrm{H}-\mathrm{L}$ & MR & $\mathrm{H}-\mathrm{L}$ & MR \\
\hline \multicolumn{11}{|c|}{ Earnings-to-price ratio \& momentum } \\
\hline Mean & $0.48 * *$ & 23.9 & 0.32 & 63.6 & $0.62^{*}$ & 0.4 & $0.51 *$ & 2.7 & 0.14 & 20.6 \\
\hline$a_{\text {CAPM }}$ & $0.47^{*}$ & 28.8 & 0.28 & 70.9 & 0.62 & 0.6 & 0.49 & 7.7 & 0.02 & 56.7 \\
\hline$a_{4 F}$ & 0.29 & 37.0 & 0.13 & 79.1 & 0.39 & 1.9 & 0.32 & 23.6 & -0.04 & 35.3 \\
\hline Sharpe ratio & 0.44 & & 0.28 & & 0.32 & & 0.39 & & 0.11 & \\
\hline \multicolumn{11}{|c|}{ Earnings-to-price ratio \& turnover ratio } \\
\hline Mean & 0.23 & 45.7 & $0.66^{*}$ & 10.1 & 0.70 & 79.6 & 0.23 & 95.8 & 0.65 & 91.4 \\
\hline$a_{\text {CAPM }}$ & 0.10 & 61.4 & 0.51 & 30.4 & 0.41 & 86.3 & -0.02 & 98.2 & 0.31 & 97.0 \\
\hline$a_{4 F}$ & 0.22 & 61.8 & $0.60^{*}$ & 32.3 & 0.67 & 82.6 & 0.18 & 95.8 & 0.50 & 94.7 \\
\hline Sharpe ratio & 0.14 & & 0.51 & & 0.34 & & 0.12 & & 0.39 & \\
\hline \multicolumn{11}{|c|}{ Earnings-to-price ratio \& skewness } \\
\hline Mean & $0.68^{* * *}$ & 30.6 & $0.60 * * *$ & 17.1 & $0.97^{* *}$ & 0.1 & $0.94^{* * *}$ & 0.0 & $0.46^{*}$ & 46.4 \\
\hline$a_{\text {CAPM }}$ & $0.66^{* * *}$ & 50.8 & $0.56^{* *}$ & 25.2 & $0.95^{* *}$ & 0.3 & $0.94^{* * *}$ & 0.0 & 0.41 & 53.6 \\
\hline$a_{4 F}$ & $0.54^{* *}$ & 68.8 & $0.47^{* *}$ & 41.1 & $0.87^{*}$ & 0.3 & $0.83^{* * *}$ & 0.0 & 0.34 & 53.1 \\
\hline Sharpe ratio & 0.70 & & 0.64 & & 0.48 & & 0.76 & & 0.44 & \\
\hline \multicolumn{11}{|c|}{ Momentum \& turnover ratio } \\
\hline Mean & 0.47 & 3.4 & $0.61^{* *}$ & 0.2 & 0.59 & 54.3 & 0.46 & 75.0 & $0.58 * *$ & 52.6 \\
\hline$a_{\text {CAPM }}$ & 0.43 & 6.0 & $0.56^{*}$ & 0.8 & 0.40 & 55.0 & 0.33 & 84.1 & 0.42 & 63.7 \\
\hline$a_{4 F}$ & 0.51 & 5.8 & $0.57^{* *}$ & 0.4 & 0.51 & 60.7 & 0.42 & 79.6 & $0.51 *$ & 56.9 \\
\hline Sharpe ratio & 0.25 & & 0.48 & & 0.27 & & 0.24 & & 0.43 & \\
\hline \multicolumn{11}{|c|}{ Momentum \& skewness } \\
\hline Mean & $0.65^{* *}$ & 3.6 & $0.44^{*}$ & 19.4 & 0.80 & 4.4 & $0.60^{*}$ & 27.7 & 0.25 & 13.4 \\
\hline$a_{\text {CAPM }}$ & $0.67^{* *}$ & 2.7 & $0.46^{*}$ & 17.9 & $0.82^{*}$ & 11.2 & $0.68^{* *}$ & 27.5 & 0.31 & 14.1 \\
\hline$a_{4 F}$ & $0.47^{*}$ & 33.3 & 0.30 & 45.8 & 0.56 & 19.0 & 0.45 & 39.2 & 0.19 & 20.4 \\
\hline Sharpe ratio & 0.55 & & 0.38 & & 0.38 & & 0.44 & & 0.19 & \\
\hline \multicolumn{11}{|c|}{ Turnover ratio \& skewness } \\
\hline Mean & $0.63^{*}$ & 4.1 & $0.88^{* * *}$ & 1.2 & $0.92^{*}$ & 0.7 & 0.54 & 0.9 & $0.68^{*}$ & 0.9 \\
\hline$a_{\text {CAPM }}$ & $0.52^{*}$ & 10.9 & $0.79 * * *$ & 7.1 & $0.70^{*}$ & 3.7 & 0.44 & 4.2 & $0.56^{*}$ & 8.2 \\
\hline$a_{4 F}$ & $0.61 *$ & 7.5 & $0.90 * * *$ & 0.8 & $0.85^{* *}$ & 1.8 & $0.54^{*}$ & 1.0 & $0.72^{* *}$ & 0.6 \\
\hline Sharpe ratio & 0.47 & & 0.88 & & 0.51 & & 0.38 & & 0.53 & \\
\hline
\end{tabular}

Note. This table reports the means, Sharpe ratios, and intercepts from the CAPM and the four-factor model of excess returns on quintile portfolios sorted in pairs of the following variables: the earnings-to-price ratio, the momentum, the reverse turnover ratio (the turnover ratio multiplied by -1), and the reverse skewness (skewness multiplied by -1). The markets are ranked according to two separate variables, and the portfolios are formed based on the sum of the ranks in both rankings. "H-L" (high minus low) is a zero-cost portfolio that is long in the high-variable markets and short in the low-variable markets. MR and p- $\neg$ values are derived from the MR test (Patton \& Timmermann, 2010). The means, intercepts, and p-values are expressed as percentages. The numbers in brackets are t-statistics based on bootstrap standard errors, and the significance at the $10 \%$ level is in bold characters. ${ }^{*},{ }^{*}$, and ${ }^{* * *}$ indicate values that are significantly different from 0 at the $10 \%, 5 \%$, and $1 \%$ levels, respectively. The Sharpe ratios are based on annualized data. 
Table 6. Mean-Variance Spanning Tests of Portfolios from Sorts on Pairs of Variables

\begin{tabular}{|c|c|c|c|c|c|c|}
\hline & EWG & EWN & CWG & CWN & LWG & LWN \\
\hline \multirow[t]{2}{*}{ Earnings-to-price ratio \& momentum } & -0.12 & $-0.28 *$ & 0.40 & 0.40 & 0.04 & -0.10 \\
\hline & $(-0.81)$ & $(-1.83)$ & $(1.27)$ & $(1.14)$ & $(0.14)$ & $(-0.44)$ \\
\hline \multirow[t]{2}{*}{ Earnings-to-price ratio \& turnover ratio } & -0.12 & -0.03 & 0.08 & 0.21 & 0.01 & 0.09 \\
\hline & $(-0.68)$ & $(-0.24)$ & $(0.21)$ & $(0.66)$ & $(0.02)$ & $(0.29)$ \\
\hline \multirow[t]{2}{*}{ Earnings-to-price ratio \& skewness } & $0.39 * *$ & 0.19 & -0.15 & -0.06 & 0.29 & -0.01 \\
\hline & $(2.58)$ & $(1.25)$ & $(-0.40)$ & $(-0.22)$ & $(1.08)$ & $(0.00)$ \\
\hline \multirow[t]{2}{*}{ Momentum \& turnover ratio } & 0.17 & 0.12 & $0.74^{*}$ & 0.25 & $0.71 *$ & 0.44 \\
\hline & $(0.42)$ & $(0.58)$ & $(1.99)$ & $(0.91)$ & $(1.86)$ & $(1.73)$ \\
\hline \multirow[t]{2}{*}{ Momentum \& skewness } & 0.08 & -0.03 & $0.83^{*}$ & 0.55 & 0.02 & 0.03 \\
\hline & $(0.51)$ & $(-0.15)$ & $(1.95)$ & $(1.23)$ & $(0.06)$ & $(0.22)$ \\
\hline \multirow[t]{2}{*}{ Turnover ratio \& skewness } & 0.25 & $0.45^{*}$ & 0.23 & 0.43 & 0.36 & 0.39 \\
\hline & $(1.01)$ & $(2.08)$ & $(0.63)$ & $(1.35)$ & $(1.19)$ & $(1.44)$ \\
\hline
\end{tabular}

Note. This table reports the intercepts from mean-variance spinning tests. The dependent variables are the return on $\mathrm{H}-\mathrm{L}$ quintile portfolios (presented and described in Table 4) from sorts on pairs of the following variables: the earnings-to-price ratio, the momentum, the reverse turnover ratio (turnover ratio multiplied by -1), and the reverse skewness (the skewness multiplied by -1). The markets are ranked according to two separate variables, and the portfolios are formed based on the sum of the ranks in both rankings. The explanatory variables include excess returns on $\mathrm{H}-\mathrm{L}$ portfolios (presented and described in Table 1) for the two constituent strategies for each double-rank strategy. The numbers in brackets are t-statistics based on bootstrap standard errors, and the significance at the $10 \%$ level is in bold characters. ${ }^{*},{ }^{* *}$, and ${ }^{* * *}$ indicate values that are significantly different from 0 at the 10\%,5\%, and 1\% levels, respectively. The Sharpe ratios are based on annualized data. The returns on portfolios are designed and calculated by six methods: equally weighted portfolios based on gross returns ("EWG"), equally weighted portfolios based on net returns ("EWN"), capitalization-weighted portfolios based on gross returns ("CWG"), capitalization-weighted portfolios based on net returns ("CWN"), liquidity-weighted portfolios based on gross returns ("LWG"), and liquidity weighted portfolios based on net returns ("LWN").

computations performed is the lack of consideration provided to cost-functions and cross-country capital mobility constraints. These aspects should be examined more carefully in future studies, specifically because they may constitute a possible explanation of the examined effect. Second, further examination is warranted on the effect of certain market-specific issues such as the level of development, integration, investors' structure, and openness. Third, certain studies suggest that various market anomalies may be influenced by seasonal effects such as the January effect. This phenomenon is defined as the tendency of stocks to perform better in January than in the remaining months of the year. This issue was investigated by Horowitz, Loughram and Savin (2000) for size, Davis (1994) for value, Loughran (1997) for the momentum effect, and Yao (2012) and Waszczuk (2013) for both value and momentum. It would be interesting to explore whether the country-level anomalies also revealed seasonal patterns. Fourth, Jacobs (2015) has recently examined whether stock-level anomalies are better explained by time-varying limits to arbitrage or sentiment. It would be valuable to repeat this exercise at the country-level because such a study could provide additional confirmation that our outcomes are sentiment driven. Finally, certain papers have suggested that the performance of stock-level anomalies could be forecasted with various variables. For example, Cohen, Polk and Vuolteenaho (2001) and Liu and Zhang (2005) have tested the utility of the so-called value spread as a predictor of future returns on value strategies. If such tools could also be applied at the country level, they could be very beneficial for international investors. 


\section{References}

Adler, M. \& Dumas, B. (1983). International portfolio choice and corporation finance: A synthesis. Journal of Finance, 38(3), 925-984. http://dx.doi. org/10.2307/2328091

AQR (2016). AQR Data Sets. Retrieved from http:// www.aqr.com/library/data-sets/betting-againstbeta-equity-factors-monthly/data

Asness, C. S., Frazzini, A. \& Pedersen, L. H. (2014, June 19). quality minus junk. Retrieved from SSRN: http://ssrn.com/abstract=2312432 or http:// dx.doi.org/10.2139/ssrn.2312432

Asness, C. S., Moskowitz ,T. J., \& Pedersen, L. H (2013). Value and momentum everywhere. Journal of Finance, 68(3), 929-985. http://dx.doi.org/10.1111/ jofi. 12021

Bali, T. G., Cakici, N., \& Fabozzi, F. J. (2013). Bookto-market and the cross-section of expected stock returns in international stock markets. The Journal of Portfolio Management, 39(2), 101-115. http:// dx.doi.org/10.3905/jpm.2013.39.2.101

Balvers, R. \& Wu, Y. (2006). Momentum and mean reversion across national equity markets. Journal of Empirical Finance, 13(1), 24-48. http://dx.doi. org/10.1016/j.jempfin.2005.05.001

Bekaert, G., \& Harvey, C. R. (2000). Foreign speculators and emerging equity markets, Journal of Finance, 55(2), 565-613. http://dx.doi.org/10.1111/00221082.00220

Bekaert, G., Harvey, C. R., \& Lundblad, C. (2007). Liquidity and expected returns: Lessons from emerging markets. Review of Financial Studies, 20(6), 1783-1831. http://dx.doi.org/10.1093/rfs/hhm030

Bhojraj, S. \& Swaminathan, B. (2006). Macromomentum: returns predictability in international equity indices. Journal of Business, 79(1), 429-451. http:// dx.doi.org/10.1086/497416

Brown, A., Du, D. Y., Rhee, S., \& Zhang, L. (2008). The returns to value and momentum in Asian markets. Emerging Markets Review, 9(2), 79-88. http:// dx.doi.org/10.1016/j.ememar.2008.02.001

Carhart, M. M. (1997). On persistence in mutual fund performance. The Journal of Finance, 52(1), 5782. http://dx.doi.org/10.1111/j.1540-6261.1997. tb03808.x

Chaieb, I. \& Errunza, V. (2007). International asset pricing under segmentation and PPP deviations.
Journal of Financial Economics, 86(2), 543-578. http://dx.doi.org/10.1016/j.jfineco.2006.06.008

Cochrane, J. H. (2005). Asset pricing. Princeton, NJ: Princeton University Press.

Cohen, R.B., Polk, C. \& Vuolteenaho, T. (2001). The value spread (Working Paper No. 8242) National Bureau of Economic Research. Retrieved from http://www.nber. org/papers/w8242. http://dx.doi.org/10.3386/w8242

Cooper, I., Sercu, P., \& Vanpée, R. (2013). The equity home bias puzzle: A survey. Foundations and Trends in Finance, 7(4), 289-416. http://dx.doi. org/10.1561/0500000039

Davis, J. (1994). The cross-section of realized stock returns: the pre-Compustat evidence. The Journal of Finance, 49(5), 1579-1593. http://dx.doi. org/10.2307/2329263

de Moor, L. \& Sercu, P. (2013). The smallest firm effect: An international study. Journal of International Money and Finance, 32, 129-155. http://dx.doi. org/10.1016/j.jimonfin.2012.04.002

Dimic, N., Orlov., V., \& Piljak, V. (2015). The political risk factor in emerging, frontier, and developed stock markets. Finance Research Letters, 15, 239245. http://dx.doi.org/10.1016/j.frl.2015.10.007

Errunza, V. \& Losq, E. (1985). International asset pricing under mild segmentation: Theory and test. The Journal of Finance, 40(1), 105-124. http://dx.doi. org/10.1111/j.1540-6261.1985.tb04939.x

Fama, E. F. \& French, K. R. (2012). Size, value, and momentum in international stock returns. Journal of Financial Economics, 105(3), 457-472. http:// dx.doi.org/10.1016/j.jfineco.2012.05.011

Gibbons, M. R., Ross, S. A., \& Shanken, J. (1989). A test of the efficiency of a given portfolio. Econometrica, 57(5), 1121-1152. http://dx.doi. org/10.2307/1913625

Goetzmann, W. N., Li, L., \& Rouwenhorst, G. (2005). Long-term global market correlations. The Journal of Business, 78(1), 1-38. http://dx.doi. org/10.1086/426518

Harvey, C. (2000). The drivers of expected returns in international markets. Emerging Markets Quarterly, 4(3), 32-49.

Harvey, C. R. (2004). Country risk components, the cost of capital, and returns in emerging markets. In S. Wilkin (Ed.), Country and political risk (pp. 71-102). London, UK: Risk Books. 
Harvey, C. R., Liu, Y. \& Zhu, H. (2015, February 3). ... and the cross-section of expected returns. Retrieved from SSRN: http://ssrn.com/abstract=2249314 or http://dx.doi.org/10.2139/ssrn.2249314

Hester, W. (2013). Fed leaves punchbowl, takes away free lunch (of international diversification). Hausman Funds Investment Research \& Insight. Retrieved from: http://www.hussmanfunds.com/rsi/ intldiversification.htm

Horowitz, J. L., Loughram, T., \& Savin, N. E. (2000). Three analyses of the firm size premium. Journal of Empirical Finance, 7(2), 143-153. http://dx.doi. org/10.1016/s0927-5398(00)00008-6

Hsu, J. \& Kalesnik, V. (2014). Finding Smart Beta in the Factor Zoo. Retrieved from https://www.researchaffiliates.com/Our\%20Ideas/Insights/Fundamentals/Pages/223_Finding_Smart_Beta_in_ the_Factor_Zoo.aspx.

Jacobs, H. (2015). What explains the dynamics of 100 anomalies? Journal of Banking and Finance, 57, 65-85. Retrieved from SSRN: http://ssrn.com/ abstract=2564706 or http://dx.doi.org/10.2139/ ssrn.2564706

Jegadeesh, N. (1990). Evidence of predictable behavior of security returns. The Journal of Finance, 45(3), 881-898. http://dx.doi.org/10.2307/2328797

Keppler, M. \& Encinosa, P. (2011). The small-country effect revisited. The Journal of Investing, 20(4), 99103. http://dx.doi.org/10.3905/joi.2011.20.4.099

Keppler, M. \& Traub, H. (1993). The small-country effect: Small markets beat large markets. The Journal of Investing, 2(3), 17-24. http://dx.doi. org/10.3905/joi.2.3.17

Kim, D. (2012). Value premium across countries. The Journal of Portfolio Management, 38(4), 75-86. http://dx.doi.org/10.3905/jpm.2012.38.4.075

Lehmann, B. N. (1990). Fads, martingales and market efficiency. The Quarterly Journal of Economics, 105(1), 1-28. http://dx.doi.org/10.2307/2937816

Liew, J. \& Vassalou, M. (2000). Can book-to-market, size and momentum be risk factors that predict economic growth? Journal of Financial Economics, 57(2), 221-245. http://dx.doi.org/10.1016/s0304$405 \mathrm{x}(00) 00056-8$

Liu, M., Liu, Q., \& Ma, T. (2011). The 52-week high momentum strategy in international stock markets. Journal of International Money and Finance,
30(1), 180-204. http://dx.doi.org/10.1016/j.jimonfin.2010.08.004

Loughram, T. (1997). Book-to-market across firm size, exchange, and seasonality: is there an effect? The Journal of Financial and Quantitative Analysis, 32(3), 249-268. http://dx.doi.org/10.2307/2331199

Liu, N. \& Zhang, L. (2005). The Value Spread as a Predictor of Returns (Working Paper No. 11326). National Bureau of Economic Research. Retrieved from http://www.nber.org/papers/w11326, http:// dx.doi.org/10.3386/w11326

Macedo, R. (1995). Country-selection style. In J. Lederman, J. \& R. A. Klein (Eds.), Equity style management: evaluating and selecting investment styles (pp. 333-355). Burr Ridge, IL: Irwin Professional Publishing

MSCI (2013). Exchange Traded Products Based on MSCI Indices Q3 2013. Retrieved from https:// www.msci.com/resources/pdfs/Exchange_Traded_Products_Based_on_MSCI_Indices.pdf

MSCI (2014a). MSCI Global market accessibility review. Retrieved from: http://www.msci.com/resources/products/indexes/global_equity_indexes/ gimi/stdindex/MSCI_Global_Market_Accessibiliy_Review_June2014.pdf

MSCI (2014b). MSCI global investable market indexes methodology. Retrieved from http://www. msci.com/eqb/methodology/meth_docs/MSCI_ Aug14_GIMIMethod.pdf

MSCI (2015). MSCI Market Classification. Retrieved from https://www.msci.com/market-classification

Novy-Marx, R. \& Velikov, M. (2014). A Taxonomy of Anomalies and their Trading Costs. (Working Paper No. 20721). National Bureau of Economic Research. Retrieved from http://www.nber.org/papers/w20721 Novy-Marx, R. (2013). The other side of value: The gross profitability premium. Journal of Financial Economics, 108(1), 1-28. http://dx.doi. org/10.1016/j.jfineco.2013.01.003

Patton, A. J. \& Timmermann, A. (2010). Monotonicity in asset returns: New tests with applications to the term structure, the CAPM, and portfolio sorts. Journal of Financial Economics, 98(3), 605-625. http://dx.doi.org/10.1016/j.jfineco.2010.06.006

Pedersen, L. H. (2015). Efficiently inefficient: How smart money invests and market prices are determined. Princeton, NJ: Princeton University Press. 
Piotroski, J. D. (2000). Value investing: the use of historical financial statement information to separate winners from losers. Journal of Accounting Research, 38, 1-41. http://dx.doi. org/10.2307/2672906

Quinn, D. P. \& Voth, H. J. (2008). A century of stock market correlations and international financial openness. American Economic Review, 98(2), 535540. http://dx.doi.org/10.1257/aer.98.2.535

Sharpe, W. F. (1964). Capital asset prices: A theory of market equilibrium under conditions of risk. The Journal of Finance, 19(3), 425-442. http://dx.doi. org/10.2307/2977928

Solnik, B. (1974). An equilibrium model of the international capital market. Journal of Economic Theory, 8, 500-524. http://dx.doi.org/10.1016/00220531(74)90024-6

Solnik, B., \& Zuo L. (2012). A global equilibrium asset pricing model with home preference. Management Science, 58(2), 273-292. http://dx.doi. org/10.1287/mnsc. 1110.1361

Stulz, R. M. (1981a). A model of international asset pricing. Journal of Financial Economics, 9(4), 383-406. http://dx.doi.org/10.1016/0304405X(81)90005-2

Stulz, R. M. (1981b) On the effects of barriers to international investment. The Journal of Finance, 36(4), 923-934. http://dx.doi.org/10.2307/2327556

Tversky, A. \& Kahneman, D. (1992). Advances in prospect theory: cumulative representation of uncertainty. Journal of Risk and Uncertainty, 5(4), 297323. http://dx.doi.org/10.1007/bf00122574

Waszczuk, A. (2013). A risk-based explanation of return patterns - Evidence from the Polish stock market. Emerging Market Review, 15, 186-210. http://dx.doi.org/10.1016/j.ememar.2012.12.002

Willenbrock, S. (2011). Diversification return, portfolio rebalancing, and the commodity return puzzle. Financial Analyst Journal, 67(4), 42-49. http:// dx.doi.org/10.2469/faj.v67.n4.1

Yao, Y. (2012). Momentum, contrarian, and the January seasonality. Journal of Banking and Finance, 36(10), 2757-2769. http://dx.doi.org/10.1016/j. jbankfin.2011.12.004

Zaremba, A., \& Konieczka, P. (2015). Are value, size and momentum premiums in CEE emerging markets only illusionary? Finance a úvěr-Czech Jour- nal of Economics and Finance, 65, 84-104. http:// dx.doi.org/10.2139/ssrn.2375454

Zaremba, A., \& Konieczka, P. (2016). Do quantitative country selection strategies really work? Journal of Investment Strategies, 5(2), 1-33. http://dx.doi. org/10.2139/ssrn.2606178

Zaremba, A., \& Nowak, A. (2015). Skewness preference across countries. Business and Economic Horizons, 11(2), 115-130. http://dx.doi.org/10.15208/ beh.2015.09

Zaremba, A. (2015a). Country selection strategies based on value, size and momentum. Investment Analyst Journal, 44(3), 171-198. http://dx.doi.org /10.1080/10293523.2015.1060747

Zaremba, A. (2015b). Country selection strategies based on quality. Country selection strategies based on quality. Managerial Finance, 41(12), 1336-1356. http://dx.doi.org/10.1108/MF-032015-0082

Zaremba, A. (2015c). Is there a low-risk anomaly across countries? Eurasian Economic Review, 6(1), 45-65. http://dx.doi.org/10.1007/s40822-015-0036-3

\section{Acknowledgments}

This study is part of project no. 2014/15/D/HS4/01235, which is financed by the National Science Center of Poland. 


\section{Appendix}

Table A1. Mean Monthly Net Returns on the Zero-Investment Portfolios Formed on Pairs of Variables within Developed and Emerging Markets

\begin{tabular}{lcccccc}
\hline Strategy & \multicolumn{3}{c}{ Developed markets } & \multicolumn{3}{c}{ Emerging markets } \\
\hline & Mean & aCAPM & a4F & Mean & aCAPM & a4F \\
\hline Earnings-to-price ratio \& momentum & 0.41 & 0.29 & 0.29 & 0.47 & 0.53 & 0.39 \\
Earnings-to-price ratio \& turnover & 0.32 & 0.28 & 0.25 & 0.65 & 0.37 & 0.52 \\
Earnings-to-price ratio \& skewness & 0.52 & 0.45 & 0.55 & 0.42 & 0.47 & 0.35 \\
Momentum \& turnover ratio & 0.30 & 0.25 & 0.31 & 0.73 & 0.85 & 0.83 \\
Momentum \& skewness & 0.51 & 0.50 & 0.53 & 0.50 & 0.54 & 0.47 \\
Turnover ratio \& skewness & 0.20 & 0.20 & 0.31 & 0.97 & 0.74 & 1.03 \\
Mean & 0.38 & 0.33 & 0.37 & 0.63 & 0.58 & 0.60
\end{tabular}

Note. This table reports the mean monthly net returns on quintile capitalization-weighted zero-investment portfolios formed from sorts on pairs of the following variables: the earnings-to-price ratio, the momentum, the reverse turnover ratio (turnover ratio multiplied by -1 ), and the reverse skewness (the skewness multiplied by -1 ). The markets are ranked according to two separate variables, and the portfolios are formed based on the sum of the ranks in both rankings. The portfolios presented here are zero-cost portfolios that are long in the high-rank markets and short in the low-rank markets. aCAPM and a4F are intercepts from the CAPM and the four-factor model, respectively. The means and intercepts are expressed as percentages. We assign markets to the "Developed Markets" category in month t when they are classified in this way for a given period by MSCI (see: https://www.msci.com/market-classification). All the remaining markets (i.e., classified by MSCl as emerging, frontier, or stand-alone) are categorized in month t as "Emerging Markets".

Table A2. Mean Monthly Net Returns on the Zero-Investment Portfolios Formed on Pairs of Variables within a Sub-Period

\begin{tabular}{lcccccc}
\hline & First half & Second half & $\begin{array}{c}\text { Pre 2007 } \\
\text { peak }\end{array}$ & $\begin{array}{c}\text { Post 2007 } \\
\text { peak }\end{array}$ & $\begin{array}{c}\text { Pre Lehman } \\
\text { Lehman }\end{array}$ & $\begin{array}{c}\text { Post } \\
\text { Lehman }\end{array}$ \\
\hline Earnings-to-price ratio \& momentum & 0.92 & 0.30 & 1.10 & 0.02 & 0.92 & 0.14 \\
Earnings-to-price ratio \& turnover & 1.48 & 1.05 & 1.63 & 0.82 & 1.50 & 0.91 \\
Earnings-to-price ratio \& skewness & 1.15 & 0.76 & 1.41 & 0.42 & 1.25 & 0.51 \\
Momentum \& turnover ratio & 1.54 & -0.02 & 1.63 & -0.30 & 1.39 & -0.21 \\
Momentum \& skewness & 1.06 & -0.22 & 1.20 & -0.53 & 0.94 & -0.39 \\
Turnover ratio \& skewness & 1.76 & 0.68 & 1.77 & 0.55 & 1.58 & 0.65 \\
Mean & 1.32 & 0.42 & 1.46 & 0.16 & 1.26 & 0.27 \\
\hline
\end{tabular}

Note. This table reports the mean monthly net return on quintile capitalization-weighted zero-investment portfolios formed from sorts on pairs of the following variables: the earnings-to-price ratio, the momentum, the reverse turnover ratio (turnover ratio multiplied by -1), and the reverse skewness (skewness multiplied by -1). The markets are ranked according to two separate variables, and the portfolios are formed based on the sum of the rank in both rankings. The portfolios presented here are zero-cost portfolios that are long in the high-rank markets and short in the low-rank markets. The means and intercepts are expressed as percentages. We calculated the return on the asset pricing factors within various sub-samples. First, we divided the research period into approximate halves (i.e., before December 31, 2006, and then after this date - the first half and the second half). Second, to show that the performance in both sub-samples was not the result of specifically chosen cut-off dates, we also used two alternative nearby dates as a basis for the division. Both dates were related to important market events: the Dow-Jones peak on the October 11, 2007 (i.e., pre-2007 peak, post-2007 peak), and the Lehman Brothers bankruptcy on September 16, 2008 (i.e., pre-Lehman, post-Lehman). 